\title{
A REVIEW OF UNIVERSAL DESIGN ON ELDERY HOUSE DESIGNS DEVELOPMENT -CASE SOUTH KOREA-
}

\author{
Bangun IR Harsritanto*) \\ *) Departemen Arsitektur, Fakultas Teknik, Universitas Diponegoro, \\ Jl. Prof. Soedarto, SH, Kampus Undip Tembalang, Semarang, Indonesia 50275
}

\begin{abstract}
Abstrak
The evolution toward Universal Design was began in the 1950s with a new attention to design for people with disabilities. At the same era South Korea began their development after several wars. Recently some of researchs and projects in South Korea which conducted on Universal Design concept are increasing in quantity and widening in multidiciplinary areas to make a better living for people in South Korea.This study examined those researches and projects to determine the progress of Universal Design principles application in South Korea in several periods and evaluated the result by the project's purpose. This study is a review from several literatures related to universal design application in South Korea.The Review revealed that South Korea has published regulations, guidelines and law based on universal design principles. South Korea has established universal design principles as fundamental basis in designing and developing their elderly residential houses. Application of universal design influenced the knowledge of diversity for people especialy in disability and elderly. Universal design encourage people with diversity in ability, ages, gender to live together without barrier to access and use every facilities in their regions.
\end{abstract}

Keywords: Universal Design, Development, South Korea, Review, Diversity

\section{Introduction}

Universal design (also called inclusive design or accessible design) is designed facility that accommodate the widest range of potential users, including people with mobility and visual disabilities and other special needs. The evolution toward Universal Design was began in the 1950 s with a new attention to design for people with disabilities. Universal design (also called inclusive design or accessible design) refers to facility designs that accommodate the widest range of potential users, including people with mobility and visual disabilities and other special needs. Universal design should be comprehensive from origin to destination for the greatest possible range of potential users. Universal design should consider all possible obstacles that may exist in buildings, transportation terminals, sidewalks, paths, roads and vehicles.

At the same era South Korea began their development after several wars South Korea is one of the countries that applied universal design principles in public spaces and public buildings. South Korea applied it to ease the access for the elderly and disabled. The condition was happened because the number of this last category in South Korea is steadily increasing due to congenital disabilities, aging and the increase of physical impairments from accidents (see table 1). In other hands, the people with disability also have the same rights to live in South Korea without any discriminations. This conditions need to be responded by the government with their authority as described on national constitutions.

The projection South Korea population based by the ages shown that number of elderly will increase constantly each year (see table 2). That condition needs to be responded by government and scientist to facilitate and anticipate the prediction. Therefore several project and research are running in this study area.

Table 1. People with Disability Employment in South Korea

\begin{tabular}{c|c|c|c}
\hline degree of disability & 2013 & 2012 & growth rate \\
\hline 1 & 423 & 492 & -14.0 \\
\hline 2 & 2,024 & 1,964 & 3.1 \\
\hline 3 & 3,301 & 3,026 & 9.1 \\
\hline 4 & 1,137 & 1,093 & 4.0 \\
\hline 5 & 1,390 & 1,239 & 12.2 \\
\hline 6 & 1,899 & 1,643 & 15.6 \\
\hline 7 & 47 & 28 & 67.9 \\
\hline overall & 10,221 & 9,485 & 7.8 \\
\hline
\end{tabular}

(Source:KEAD, 2013) 
In aims to anticipate and facilitate the elderly and disability right, South Korea starts to study and apply universal design principles on every buildings and public facilities from early 80 's as the rise of Korea development begins. South Korea together with China and Japan were developed universal design for the three nations, with the aims having standard adopted the worldwide.

Following those trends and focused on South Korea, this study examined those researches and projects progress of Universal Design principles application in South Korea in several periods and evaluated the result by the project's purpose. In other means, this study review from several literatures related to universal design application in South Korea.

\section{Universal Design Study in South Korea}

Universal design is worldwide design movement as support for independence and participation has evolved in response to demographic expand and social condition of more people living with a wide range of disabilities and various health conditions than before and the longest lifespans in records. Universal Design is the design of products, environments, and communication to be usable by all people, to the maximal extent possible, without adaptation or specialized design. The concept is also called inclusive design, design-for-all, lifespan design or human-centered design.

Table 2. Population of Elderly in South Korea

\begin{tabular}{|c|c|c|c|c|c|c|}
\hline \multirow{2}{*}{ Period } & \multirow{2}{*}{$\begin{array}{l}65 \text { or } \\
\text { more }\end{array}$} & \multirow{2}{*}{ Males } & & \multirow{2}{*}{ Females } & & \multirow{2}{*}{ Sex ratio } \\
\hline & & & Share & & Share & \\
\hline 1990 & 2195 & 882 & 3.8 & 1373 & 6.4 & 59.8 \\
\hline 2000 & 3395 & 1300 & 9.5 & 2095 & 9 & 62 \\
\hline 2010 & 5452 & 2227 & 9 & 3225 & 13.1 & 69.1 \\
\hline 2014 & 6366 & 2658 & 10.5 & 3728 & 14.8 & 71.3 \\
\hline 2020 & 8084 & 3451 & 13.5 & 4633 & 18 & 74.5 \\
\hline 2030 & 12691 & 5682 & 21.9 & 7010 & 26.7 & 81.1 \\
\hline 2040 & 16501 & 7460 & 29.5 & 9041 & 35 & 82.5 \\
\hline 2050 & 17991 & 8151 & 34.3 & 9841 & 40.4 & 82.8 \\
\hline 2060 & 17662 & 8197 & 37.7 & 9425 & 42.5 & 87 \\
\hline
\end{tabular}

(Source: Statistic Korea Population Projection, 2011)

Universal design is a philosophy of design which removed distinctions among varying abilities by adhering to four major principles which identified by Ron Mace as follows:
1. supportive: it makes environments work for the individual, stressing ease of use and maintenance.

2. adaptable: it serves a wide range of users whose needs change over time.

3. accessible: the everyday comforts and conveniences that "normal" individuals enjoy are provided to all users of the environment. Codes and ADA (Americans with Disabilities Act) guidelines for accessibility are minimal and the interpretation of accessibility is frequently limited to providing access to buildings for people with impaired mobility.

4. safety: it not only provides environments and tools for the presently disabled, but also anticipates and prevents disabilities such as repetitive strain injuries.

The further developments of these principles have provided a standard to the products and environments which can be measured (Null, 2014). As the movement has grown, universal design principles have continually been evaluated and refined. The center for universal design at North Carolina developed an expanded list of seven principles of universal design which were represented by ten UD advocates as : Bettye Rose Connell, Mike Jones, Ron Mace, Jim Mueller, Abir Mullick, Elaine Ostroff, Jon Sanford, Ed Steinfeld, Molly Story, and Greg Vanderheiden. The list of seven principles of universal design are :

1. Equitable Use :

The design is useful and marketable to people with diverse abilities.

2. Flexibility in Use :

The design accommodates a wide range of individual preferences and abilities.

3. Simple and Intuitive Use :

Use of the design is easy to understand, regardless of the user's experience, knowledge, language skills, or current concentration level.

4. Perceptible Information :

The design communicates necessary information effectively to the user, regardless of ambient conditions or the user's sensory abilities.

5. Tolerance for Error :

The design minimizes hazards and the adverse consequences of accidental or unintended actions.

6. Low Physical Effort :

The design can be used efficiently and comfortably and with a minimum of fatigue.

7. Size and Space for Approach and Use :

Appropriate size and space is provided for approach, reach, manipulation, and use regardless of user's body size, posture, or mobility. 
The application of Universal design principles in South Korea has been performed in several case and multidisciplinary views, such:

\section{Residential facilities}

South Korea has developed many guideline and projects conducting silver town for elderly and kitchen for wheelchair access. The integrations of those study can be explained in this section. The kitchen studies were devided by two approach :

1) pre design study,

2) post occupancy evaluation which resulted more universal design kitchen without specialized for wheelchair users. The universal design concepts were developed into $4+3$ principles whice derivated from 4 principles universal design plus 3 as described on figure 1.

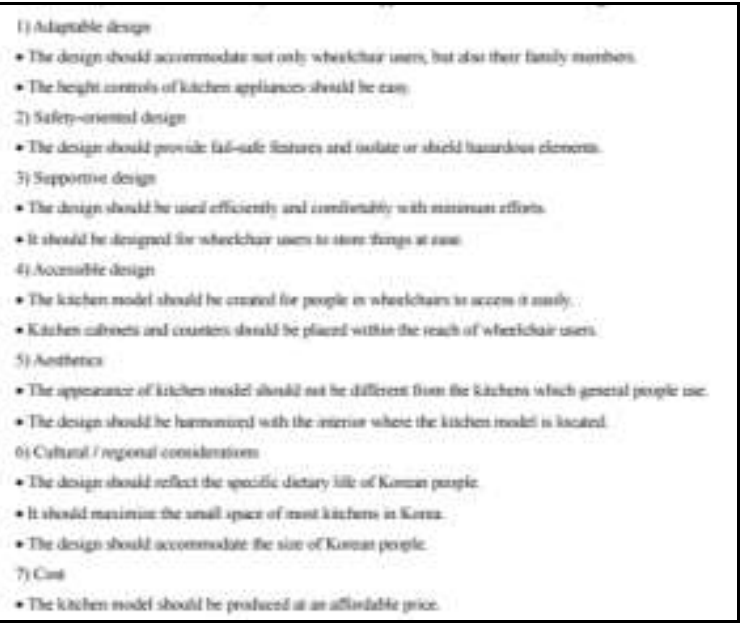

Figure 1. universal kitchen design concepts source : Ko, Young-Jun (2001)

This study found remodelling kitchen set which fit to Korea dietary life and affordable to be installed in apartements. This study suggested applicable alternatives for five unit types without increasing the current kitchen size. From this, the possibility for designing a more universal kitchen within the current kitchen area size has been demonstrated. Thus, it could be concluded that the usability and accessibility of the spatial layout of a kitchen would be more easily affected by the spatial distribution of appliances and the relationship between them than the size and shape of the kitchen. Therefore, for the application of universal design to kitchen design, considerations not only of the size and shape of the kitchen and its appliances, but also of clear floor space, work triangle, countertop, reach range, and knee clearance formed by the location of each appliance are required.

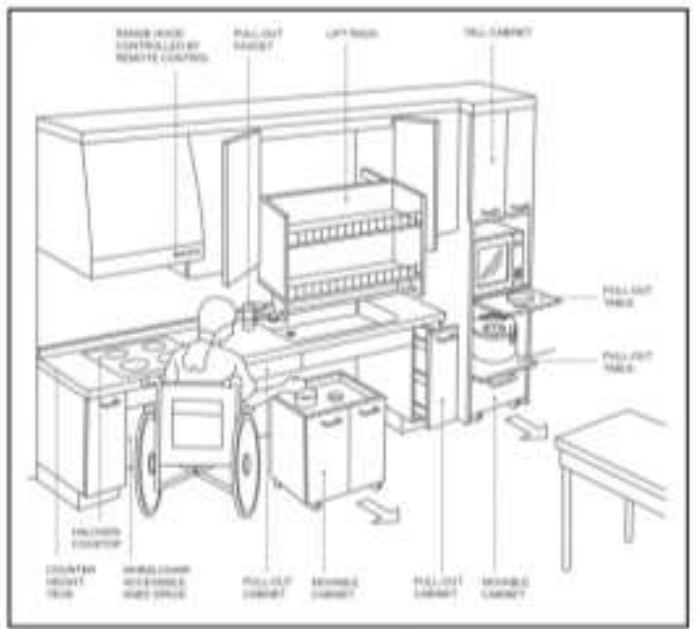

Figure 2. Kitchen sets integrated with korea dietary life

source : Ko, Young-Jun (2001)

The kitchen set design in bigger case can be applied as part of elderly house design or silvertown with some modification related the character, capacity and minimum facility that required by the house. The approach to elderly who have disability and low physical ability was applied in every rooms and spaces in this elderly house.

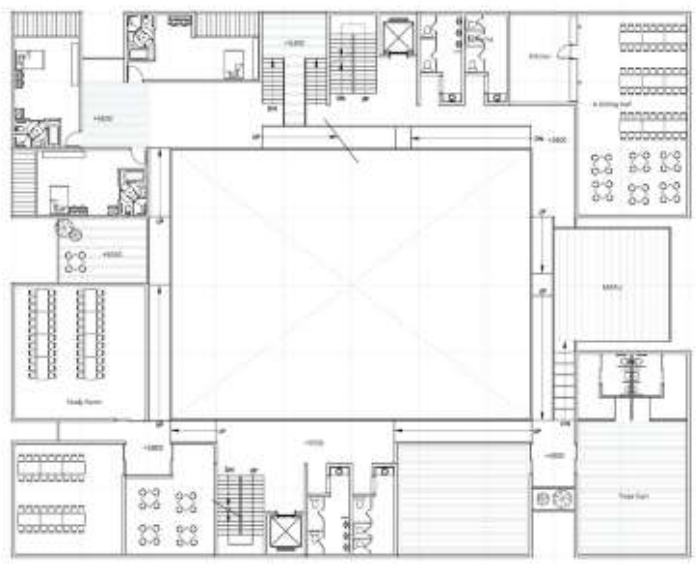

Figure 3. Integrated elderly unit design source : sora, lee (2012)

The elderly houses is not just single support building. The concepts of integrity in living were promoted the house into city part which need to be connected with openspace and community center (see figure 4). 


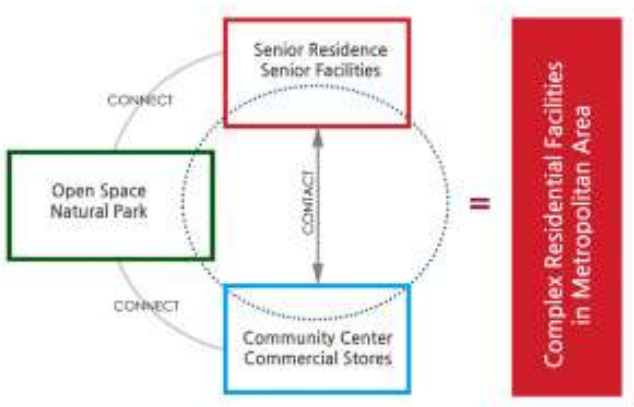

Figure 4. Integrated elderly house concept source : sora, lee (2012)

The Impact of Universal Design in South Korea

The establishment of Universal Design in South Korea specialy in three sector mentioned above shown that the application is well installed and still developing into perfections.

In elderly housing (silver town) the relation between traditional habit of the occupant shown that universal design research can be started from specialized design to enrich the knowledge itself. The lift rack, lowered counter (sink), movable cabinet (under the cooktop), pullout cabinet, halogen cooktop, pullout tables which designed to facilite the disable people, can be used also by common people of not disable user.

Along with the objective evaluations both in universal design and cultural aspects, subjective questions asking the usefulness on key elements such as counter height, knee spaces, movable cabinets, pull out tables, and lift rack etc., were given. As a result, the kitchen model was verified to be useful in many ways, and some problems were also pointed out that need more adjustment to meet the universal design principles (see table 7).

Table 7. Universal reach range

\begin{tabular}{ll}
\hline Design element & Requirements \\
\hline Universal reach range (vertical) & $380-1,400 \mathrm{~mm}$ \\
Universal reach range (horizontal) & $6610 \mathrm{~mm}$ \\
Height of countertop & $760-860 \mathrm{~mm}$ \\
Depth of countertop & $410-610 \mathrm{~mm}$ \\
Clearance between work surface and wall & $>380 \mathrm{~mm}$ \\
cabinet & \\
Obstruction by projected base cabinet & $255 \mathrm{~mm}$ \\
\hline
\end{tabular}

The kitchen study can be widen into house criteria with dynamic range of universal reach and applied in every elderly housing in South Korea. The application itself already reach every province in Korea. Especialy at Gyeonggi (153), Chungbuk (42), Gangwon (34), Jeonnam (33) and Gyeongbuk province (32), eventhough not all elderly house applied this design. (see figure 6)
This situation showed that the development of elderly house in South Korea is not centered in Seoul as capitol district. Nevertheles the domination of elderly house is located in Gyeonggi province which known as the satellite province of the capitol district of South Korea

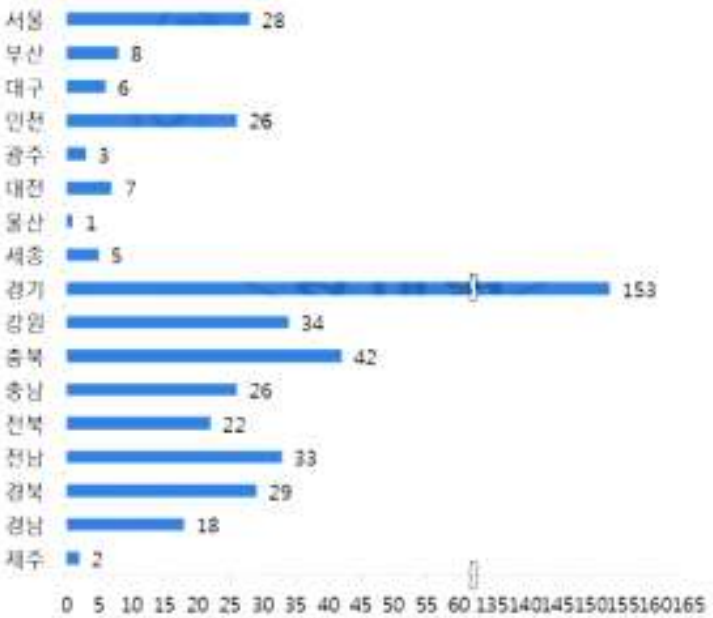

\section{Figure 6 Universal Design applied Elderly Housing in South Korea}

The redevelopment of kitchen in elderly housing shown that only $3.7 \%$ elderly feel uncovinient with the kitchen and 54,9\% didn't feel uncomfort in the house. The next big issues which need to be develop are stairs $(15,3 \%)$, toilets $(12.55 \%)$ and entrances $(9,1 \%)$ at their houses (see figure 7). This situation means house in South Korea is relatively safe to be lived and accessible due to the application of universal design principles which injected especialy to the elderly house in every province of South Korea. As shown in the figure 7, the stairs, toilets and entrances were identified as unconvinient places since these three are designed with different in floor level compare to the other rooms in elderly house.

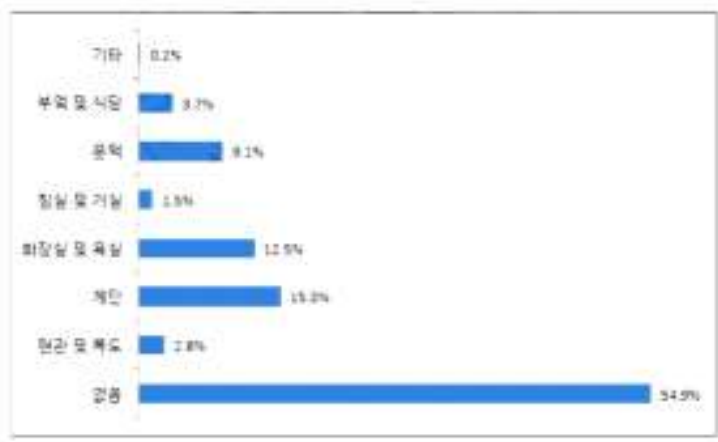

Figure 7. Elderly uncovinient places in house 


\section{Conclussion}

The Review revealed that South Korea has published regulations, guidelines and law based on universal design principles. South Korea has established universal design principles as fundamental basis in designing and developing their elderly residential houses. The developments are not focused at the capitol district. Application of universal design influenced the knowledge of diversity for people especialy in disability and elderly. Universal design encourage people with diversity in ability, ages, gender to live together without barrier to access and use every facilities in their regions

\section{References}

Aslaksen (1997) Universal design: Planning and Design for All, Cornel Univeristy (http://digitalcommons.ilr.cornell.edu/gladnetcoll ect)Feng, li et al (2011) Study on the universal design for pedestrian space - Emphasis on Seoul's public space design, Korean Institute of Interior Design 13(3) pp 70-74

Goldsmith, Selwyn (2000) Universal Design: A Manual Of Practical Guidance For Architects, Architectural Press, Oxford

Ko, Jung Yeong (2011) Development of Kitchen Models for Wheelchair Users -Focused on the Development and Evaluation of a System Kitchen Model Which Reflects Conditions of Korea and Universal Design Concepts- accessed at

http://www.idemployee.id.tue.n1/g.w.m.rauterber g/conferences/cd_donotopen/adc/final_paper/031 .pdf\&prev=search

Kang, Kyung-Yeon et al(2016) Application of Universal Design in the Design of Apartment Kitchens, Journal of Asian Architecture and Building Engineering vol.15 no.3

Lee, Sora et al (2011) A Study on Urban Complex Residential Facility for the Elderly Based on Universal Design Concept, Hanyang University Journal of Aging Society 2011 Vol. 2, No. 1, pp. 51-82.

Jeong, Byung Yong et al(2014). Workplace Universal Design for the Older Worker. Journal of Ergonomic Society of Korea, 33(5), 365-376.

Moon, In-Young et al (2014) The Evaluation of the Village Community Center in Aspects of Universal Design Principles - Focused on 25 Village Community Centers in Hwasoon Province, Korean Institute Of Interior Design Journal 23(1) pp 162-171

North Caroline State University, College of Design (1997). The Center For Universal Design, Retrieved $21 \quad$ May 2010 from http://www.design.ncsu.edu/cud.
Null, Roberta (2014) Universal design Principles and Models, Taylor \& Francis Group

Shin, Han-Na (2011) A Study on the Usability Evaluation of Universal Design Environment based on Needs for Elderly Housing in Seoul, Korean Institute of Interior Design, 13(3), pp 3842

Saito, Y., Awareness of universal design among facility managers in Japan and the United States, Automation in Construction, 15(4), 462-478, 2006. doi:10.1016/j.autcon.2005.06.013 